\title{
Sensitivity analysis of point and parametric pedotransfer functions for estimating water retention of soils in Algeria
}

\author{
Sami Touil ${ }^{1,2,3}$, Aurore Degre $^{2}$, and Mohamed Nacer Chabaca ${ }^{1}$ \\ ${ }^{1}$ Superior National School of Agronomy, El Harrach, Algiers, Algeria \\ ${ }^{2}$ Gembloux Agro-Bio Tech, Biosystem Engineering, Soil-Water-Plant Exchanges, University of Liege, \\ Passage des Déportés, Gembloux, Belgium \\ ${ }^{3}$ Laboratory of Crop Production and Sustainable Valorization of Natural Resources, University of Djilali \\ Bounaama Khemis Miliana, Ain Defla, Algeria
}

Correspondence to: Sami Touil (touil_sy@ hotmail.fr)

Received: 16 March 2016 - Published in SOIL Discuss.: 7 April 2016

Revised: 15 November 2016 - Accepted: 17 November 2016 - Published: 15 December 2016

\begin{abstract}
Improving the accuracy of pedotransfer functions (PTFs) requires studying how prediction uncertainty can be apportioned to different sources of uncertainty in inputs. In this study, the question addressed was as follows: which variable input is the main or best complementary predictor of water retention, and at which water potential? Two approaches were adopted to generate PTFs: multiple linear regressions (MLRs) for point PTFs and multiple nonlinear regressions (MNLRs) for parametric PTFs. Reliability tests showed that point PTFs provided better estimates than parametric PTFs (root mean square error, RMSE: 0.0414 and $0.0444 \mathrm{~cm}^{3} \mathrm{~cm}^{-3}$, and 0.0613 and $0.0605 \mathrm{~cm}^{3} \mathrm{~cm}^{-3}$ at -33 and $-1500 \mathrm{kPa}$, respectively). The local parametric PTFs provided better estimates than Rosetta PTFs at $-33 \mathrm{kPa}$. No significant difference in accuracy, however, was found between the parametric PTFs and Rosetta $\mathrm{H} 2$ at $-1500 \mathrm{kPa}$ with RMSE values of $0.0605 \mathrm{~cm}^{3} \mathrm{~cm}^{-3}$ and $0.0636 \mathrm{~cm}^{3} \mathrm{~cm}^{-3}$, respectively. The results of global sensitivity analyses (GSAs) showed that the mathematical formalism of PTFs and their input variables reacted differently in terms of point pressure and texture. The point and parametric PTFs were sensitive mainly to the sand fraction in the fine- and medium-textural classes. The use of clay percentage $(\mathrm{C} \%)$ and bulk density (BD) as inputs in the medium-textural class improved the estimation of PTFs at $-33 \mathrm{kPa}$.
\end{abstract}

\section{Introduction}

Predictive information on the spatial distribution of soil water and its availability for plants enables producers to take effective decisions (e.g. on nutrient management and plant cover) to maximise profitability. The soil-water balance is central to many processes that influence plant growth and the degradation of soil and water resources.

Hydrologists face the situation where soil hydraulic data such as water retention or hydraulic conductivity are often missing. Therefore, pedotransfer functions (PTFs) are used as an alternative to estimate these properties. The extrapolation of PTFs in different agropedoclimatic context limits their performance (Touil et al., 2016). The development of local PTFs could be useful in meeting the agricultural requirements for modelling with reasonable accuracy.

Soil water retention (SWR) curves can usually be estimated using two approaches: point PTFs and parameter PTFs. With point PTFs, SWR is estimated at defined pressure points (Pachepsky et al., 1996; Minasny et al., 1999). One of the most commonly used SWR curves is the van Genuchten (1980) model. With parameter PTFs, the parameters of SWR models, such as $\theta_{\mathrm{S}}, \theta_{\mathrm{r}}, \alpha$ and $n$, are estimated by fitting them to the data and then relating them by empirical correlation to basic soil properties (Vereecken et al., 1992; Wösten et al., 1995; Schaap and 

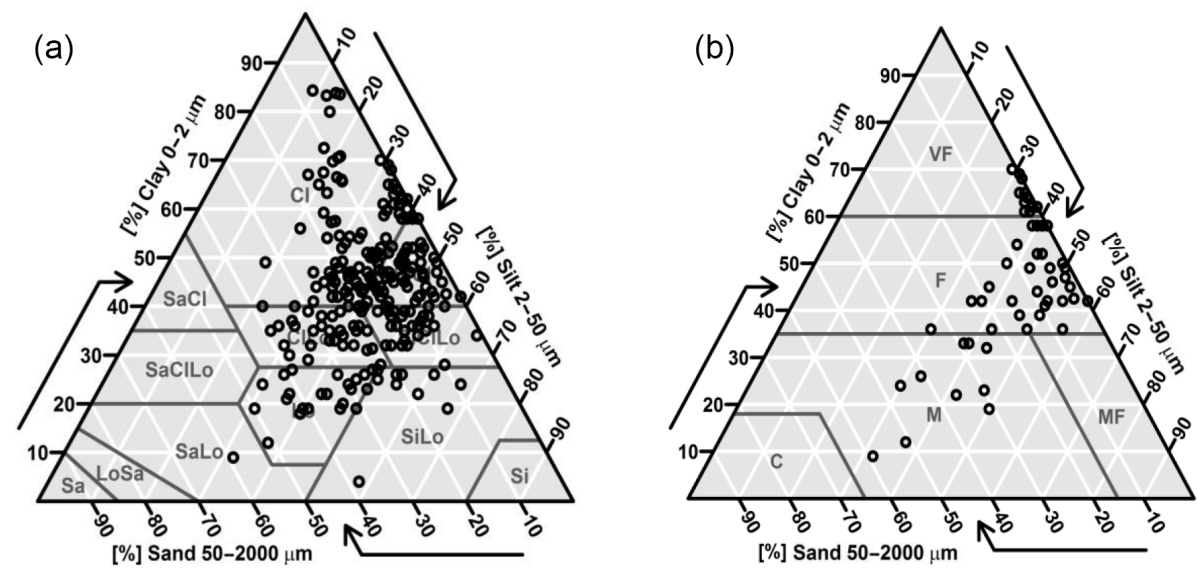

Figure 1. (a) Texture fractions of the dataset (242 samples), based on the USDA system. (b) Particle size distribution of 53 soil samples from Algeria according to the FAO textural triangle (FAO, 1990).

Leij, 1998; Minasny and McBratney, 2002; Rawls and Brakensiek, 1985; van Genuchten et al., 1992; Wösten et al., 2001; Vereecken et al., 2010). Schaap et al. (2001) developed the Rosetta package based on the artificial neural network (ANN) method, which uses five hierarchical models to predict the van Genuchten (VG) parameters $\left(\theta_{\mathrm{s}}, \theta_{\mathrm{r}}, \alpha\right.$ and $\left.n\right)$ with only soil texture classes and the input data (texture, bulk density, $\mathrm{BD}$, and one or two water content values at -33 and $-1500 \mathrm{kPa})$.

PTFs for point and parametric estimation of SWR from basic soil properties can be developed using multiple regression methods (Lin et al., 1999; Mayr and Jarvis, 1999; Tomasella et al., 2000).

Some $97 \%$ of water retention PTFs for soils in the tropics are based on multiple linear and polynomial regressions of $n$ th-order techniques (Botula et al., 2014).

Using PTFs in environments that differ from those from which they were derived can lead to an under- or overestimation of SWR. Several studies have shown that SWR is a complex function of soil structure and composition (Rawls et al., 1991, 2003; Wösten et al., 2001; Mirus, 2015). Applying PTFs to different textural or structural classes could also be a source of uncertainty (Bruand et al., 2002; Pachepsky and Rawls, 2003). SWR and hydraulic conductivity vary widely and nonlinearly with soil water potential. Soil texture is the main determinant of the water-holding characteristics of most agricultural soils (Saxton et al., 1986). The relationship between the SWR curve and particle size distribution (PSD) has been investigated in many studies (Jonasson, 1992; Minasny et al., 2007; Ghanbarian-Alavijeh et al., 2009; Yang and You, 2013; Lee and Ro, 2014). SWR depends mainly on texture, with other factors such as BD, structure, organic matter (OM), clay type and hysteresis having a secondary impact (Williams et al., 1983; Saxton et al., 1986; Vereecken et al., 1989; Winfield et al., 2006).
The variability in PTF response depends on the variability and uncertainty of one or more of the input variables. Uncertainty analysis in the variety of available PTF approaches is necessary to minimise error in estimation and identify its source. Recently, sensitivity analysis techniques and uncertainty analysis have begun to receive considerable attention in PTF studies (Nemes et al., 2006; Kay et al., 1997; Grunwald et al., 2001; Deng et al., 2009; Moeys et al., 2012; Loosvelt et al., 2013). The question is as follows: which variable input is the main or best complementary predictor of SWR, and at which potential? Global sensitivity analysis (GSA) enables us to study how uncertainty in the output of a model can be apportioned to different sources of uncertainty in the model inputs (Saltelli et al., 2000). Generally, GSA is useful for identifying which variables make the main contribution to output variables (Jacques et al., 2006).

The objectives of this study were to

- develop and validate two PTF approaches using regression methods: point PTFs for estimating SWR in Algerian soils at -33 and $-1500 \mathrm{kPa}$ and parametric PTFs for estimating the VG parameters

- study the impact of each input on the PTF responses.

\section{Materials and methods}

\subsection{The database}

The soil dataset used for this study was collected from various regions in Algeria, mainly in the north, which has a Mediterranean climate. It contained 242 samples, with basic soil properties: texture fractions (based on the USDA system; clay and silty-clayey for most of the soils; Fig. 1a), BD, OM percentage and water content at -33 and $-1500 \mathrm{kPa}$. Descriptive statistics of the development and validation datasets are presented in Table 1 . The available database 
Table 1. Soil characteristics of the developed and validated datasets.

\begin{tabular}{|c|c|c|c|c|c|c|c|}
\hline & \multicolumn{3}{|c|}{ PSD } & \multirow[b]{2}{*}{$\begin{array}{c}\mathrm{BD} \\
\left(\mathrm{g} \mathrm{cm}^{3}\right)\end{array}$} & \multirow[b]{2}{*}{$\begin{array}{l}\mathrm{OM} \\
(\%)\end{array}$} & \multicolumn{2}{|c|}{$\operatorname{VWC}\left(\mathrm{cm}^{3} \mathrm{~cm}^{-3}\right)$} \\
\hline & $\begin{array}{r}S \\
(\%)\end{array}$ & $\begin{array}{r}\mathrm{Si} \\
(\%)\end{array}$ & $\begin{array}{r}\mathrm{C} \\
(\%)\end{array}$ & & & $-33 \mathrm{kPa}$ & $-1500 \mathrm{kPa}$ \\
\hline \multicolumn{8}{|c|}{ Samples used for deriving PTF $(n=189)$} \\
\hline Average & 17.81 & 39.23 & 42.97 & 1.71 & 0.95 & 0.44 & 0.27 \\
\hline Standard deviation & 10.32 & 10.76 & 13.90 & 0.20 & 0.93 & 0.09 & 0.08 \\
\hline Minimum & 1.00 & 9.20 & 4.00 & 0.60 & 0.08 & 0.13 & 0.03 \\
\hline Maximum & 50.00 & 67.00 & 84.30 & 2.10 & 8.40 & 0.73 & 0.56 \\
\hline Coefficient of variation & 0.58 & 0.27 & 0.32 & 0.12 & 0.98 & 0.21 & 0.31 \\
\hline \multicolumn{8}{|c|}{ Samples used for testing PTF $(n=53)$} \\
\hline Average & 12.50 & 41.58 & 45.92 & 1.49 & 0.87 & 0.40 & 0.21 \\
\hline Standard deviation & 14.84 & 7.62 & 14.94 & 0.13 & 0.50 & 0.10 & 0.07 \\
\hline Minimum & - & 29.00 & 9.00 & 1.15 & 0.20 & 0.14 & 0.07 \\
\hline Maximum & 59.00 & 58.00 & 70.00 & 1.73 & 2.74 & 0.57 & 0.45 \\
\hline Coefficient of variation & 1.19 & 0.18 & 0.33 & 0.09 & 0.57 & 0.24 & 0.35 \\
\hline
\end{tabular}

PSD: particle size distribution, S: sand, Si: silt, C: clay, BD: bulk density, OM: organic matter, VWC: volumetric water content.

was split into two datasets. Subset 1 , which was used to develop the PTFs, contained $78.1 \%$ of the samples. Used as the calibration set, they were collected from the coastal plain of Annaba in north-eastern Algeria (13 samples), the Beni Slimane plain of Media (42 samples), the Kherba El Abadia plain of Ain Defla (54 samples) and the Lower Cheliff plain in north-western Algeria (80 samples). Subset 2 contained the remaining $21.9 \%$ of the samples. Used to verify the PTFs, they were collected from Benziane valley in the lower south-western Cheliff plain. The depth of the two upper horizons varied from site to site, with a maximum of $30 \mathrm{~cm}$ for surface horizons and more than $30 \mathrm{~cm}$ for subsurface horizons.

Particle size distribution (PSD) analysis was conducted using the international Robinson's pipette method (Robinson, 1922). Undisturbed soil samples obtained with 500$1000 \mathrm{~cm}^{3}$ cylinders were used to determine BD. The SWR values at -33 and $-1500 \mathrm{kPa}$ were obtained using Richards' apparatus (Richards and Fireman, 1943). Undisturbed soil samples were collected near field capacity with $100 \mathrm{~cm}^{3}$ cylinders. Water content was measured using the gravimetric method at $105^{\circ} \mathrm{C}(24 \mathrm{~h})$. Organic carbon content was determined using the wet oxidation method (Walkley and Black, 1934). Variation in soil texture in the dataset is displayed using the textural triangle proposed by FAO (1990) in Fig. 1b.

The SWR model devised by van Genuchten (1980) is defined as

$\theta(h)=\theta_{\mathrm{r}}+{\frac{\theta_{\mathrm{s}}-\theta_{\mathrm{r}}}{\left(1+|\alpha h|^{n}\right)}}^{m}$,

where $\theta_{\mathrm{r}}$ and $\theta_{\mathrm{S}}$ are residual and saturated soil-water content $\left(\mathrm{cm}^{3} \mathrm{~cm}^{-3}\right)$, respectively, and $\alpha\left(\mathrm{cm}^{-1}\right)$ and $n$ are the shape factors of the SWR function. The VG parameters were in- directly estimated for each soil sample from four levels of measured data inputs: sand, silt and clay percentages, and BD using the Rosetta model H3 (Schaap et al., 2001). The $m$ parameter was calculated as follows:

$m=1-1 / n$.

\subsection{PTF development}

Two approaches were used in this study to develop the PTFs: point PTFs for estimating SWR for particular points of pressure $(h)$ and parametric PTFs for predicting the VG parameters. Each water content level at selected water potentials of -33 and $-1500 \mathrm{kPa}$ and estimated VG parameters were related to basic soil properties (i.e. sand, silt, clay content, OM content and BD) using multiple regression techniques (Table 2). The most significant input variables were determined using the Pearson correlation $(\alpha=5 \%)$. For the multiple linear regression (MLR) models, the general form of the resulting equations was thus expressed as

$Y=a_{0}+b_{1} X_{1}+b_{2} X_{2}+b_{3} X_{3}+b_{4} X_{4}$.

For the multiple nonlinear regression (MNLR) models, it was thus expressed as

$$
\begin{aligned}
Y & =a_{0}+b_{1} X_{1}+b_{2} X_{2}+b_{3} X_{1}^{\wedge} 2+b_{4} X_{2}^{\wedge} 2+b_{5} X_{1}^{\wedge} 3 \\
& +b_{6} X_{2}^{\wedge} 3+b_{7} X_{1} \cdot X_{2}+b_{8} X_{1}^{\wedge} 2 \cdot X_{2}+b_{9} X_{1} \cdot X_{2}^{\wedge} 2,
\end{aligned}
$$

where $Y$ represents the dependent variable, $a_{0}$ is the intercept, $b_{1} \ldots, b_{n}$ are the regression coefficients, and $X_{1}$ to $X_{4}$ refer to the independent variables representing the basic soil properties. 
Table 2. Developed pedotransfer functions (PTFs).

\begin{tabular}{|c|c|}
\hline \multicolumn{2}{|r|}{ Point PTFs } \\
\hline $\begin{array}{l}\text { at }-33 \mathrm{kPa}: \\
\text { at }-1500 \mathrm{kPa}:\end{array}$ & $\begin{array}{l}\theta=0.0246-0.0040 \mathrm{~S}+0.0012 \mathrm{C}+0.2554 \mathrm{BD}+0.0067 \mathrm{OM} \\
\theta=-0.0627-0.0029 \mathrm{~S}+0.00165 \mathrm{C}+0.1837 \mathrm{BD}+0.0017 \mathrm{OM}\end{array}$ \\
\hline \multicolumn{2}{|r|}{ Parametric PTFs } \\
\hline $\begin{array}{l}\theta_{\mathrm{s}}=0.44-0.0 \\
\theta_{\mathrm{r}}=0.09+0.0 \\
\alpha=0.003-0 . \\
+0.0000077 \mathrm{~S} \\
n=2.9-0.00 \\
-0.000015 \mathrm{Si}^{?}\end{array}$ & $\begin{array}{l}13369 \mathrm{~S}+0.0002 \mathrm{C}+0.01771343 \mathrm{BD}-0.0018272 \mathrm{OM} \\
0777943 \mathrm{~S}-0.000319883 \mathrm{C}+0.000063602 \mathrm{~S}^{2}+0.000012 \mathrm{C}^{2}+0.00000093 \mathrm{~S}^{3}-0.0000001 \mathrm{C}^{3} \\
001 \mathrm{~S}+0.000089 \mathrm{Si}+0.0000054 \mathrm{~S}^{2}-0.0000045 \mathrm{Si}^{2}-0.000000073 \mathrm{~S}^{3}+0.000000045 \mathrm{Si}^{3} \\
\mathrm{i}-0.000000031 \mathrm{~S}^{2} \mathrm{Si}-0.000000062 \mathrm{~S} \mathrm{Si}^{2} \\
77395 \mathrm{C}-0.09478943 \mathrm{Si}-0.00036644 \mathrm{C}^{2}+0.00202592 \mathrm{Si}^{2}+0.00000249 \mathrm{C}^{3} \\
+0.00028374 \mathrm{CS}+0.00000491 \mathrm{C}^{2} \mathrm{Si}-0.00000532 \mathrm{C} \mathrm{Si}^{2}\end{array}$ \\
\hline
\end{tabular}

S: sand (\%), C: clay (\%), Si: silt (\%), BD: bulk density $\left(\mathrm{g} \mathrm{cm}^{-3}\right), \mathrm{OM}$ : organic matter $(\%), \theta_{\mathrm{r}}$ and $\theta_{\mathrm{s}}$ are residual and saturated soil-water content $\left(\mathrm{cm}^{3} \mathrm{~cm}^{-3}\right)$, respectively, and $\alpha\left(\mathrm{cm}^{-1}\right)$ and $n$ are the shape factors of the of van Genuchten model.

The prediction quality of the point and parametric PTFs developed from Algerian soils were then compared with three Rosetta PTFs (H1, H2 and H3). We chose the Rosetta model because it gives the user flexibility in inputting the data required (Stumpp et al., 2009), with the option of five levels based on input data (Schaap et al., 2001):

- H1 is textural classes (USDA system).

- H2 is clay + silt + sand.

$-\mathrm{H} 3$ is clay + silt + sand $+\mathrm{BD}$.

- H4 is clay + silt + sand $+\mathrm{BD}+$ volumetric water at $-33 \mathrm{kPa}$.

- H5 is clay + silt + sand $+\mathrm{BD}+$ volumetric water at $-33 \mathrm{kPa}+$ volumetric water at $-1500 \mathrm{kPa}$.

The artificial neural network models were also chosen because they have given reasonable predictions in several evaluation studies (e.g. Nemes et al., 2003). In our study, the three Rosetta model levels (H1, H2 and H3) were selected to compare their performance in the Algerian soils because they require only texture data and $\mathrm{BD}$ as inputs, like locally developed PTFs do.

\subsection{Evaluation criteria}

PTFs are regularly assessed by comparing the values that they predict with the measured values (Pachepsky et al., 1999; FAO, 1990). In order to assess the validity of the PTFs developed, we used the following criteria: mean prediction error (ME) to indicate the bias of the estimate, root mean square error (RMSE) to assess the quality of the prediction (it is frequently used in studies on PTFs), and the index of agreement $(d)$ developed by Willmott and Wicks (1980) and Willmott (1981) as a standardised measure of the degree of model prediction error. They were calculated using the following equations, respectively:

$\mathrm{ME}=\frac{1}{N} \sum_{i=1}^{n}\left(\theta_{\mathrm{p}}-\theta_{\mathrm{m}}\right)$,

where $N$ is the number of horizons, and $\theta_{\mathrm{p}}$ and $\theta_{\mathrm{m}}$ predicted and measured volumetric water content, respectively. The estimate was better when ME was close to $0^{\prime}$. Negative ME values indicated an average underestimation of $\theta_{\mathrm{m}}$, whereas positive values indicated overestimation.

$\mathrm{RMSE}=\left\{\frac{1}{n} \sum_{i=1}^{n}\left(\theta_{\mathrm{p}}-\theta_{\mathrm{m}}\right)^{2}\right\}^{\frac{1}{2}}$

Thus, the lower the RMSE the better the estimate.

$d=1-\frac{\sum_{i=1}^{n}\left(\theta_{\mathrm{p}}-\theta_{\mathrm{m}}\right)^{2}}{\sum_{i=1}^{n}\left[\left|\left(\theta_{\mathrm{p}}-\bar{\theta}_{\mathrm{m}}\right)\right|+\left|\left(\theta_{\mathrm{m}}-\bar{\theta}_{\mathrm{m}}\right)\right|\right]^{2}}$

The index of agreement varied from 0 to 1 , with higher index values indicating that the modelled values $\theta_{\mathrm{p}}$ were in better agreement with the observations $\theta_{\mathrm{m}}$.

\subsection{Global sensitivity analysis}

Global sensitivity analysis (GSA) involves determining which part of the variance in model response is due to variance in which input variables or groups of inputs. The impact of the parameters is quantified by calculating the global sensitivity indices.

The Sobol method (Sobol, 1990) is an independent GSA method based on decomposition of the variance. When the model is nonlinear and non-monotonic, the decomposition of the output variance is still defined and can be used. The Sobol model is represented by the following function: 

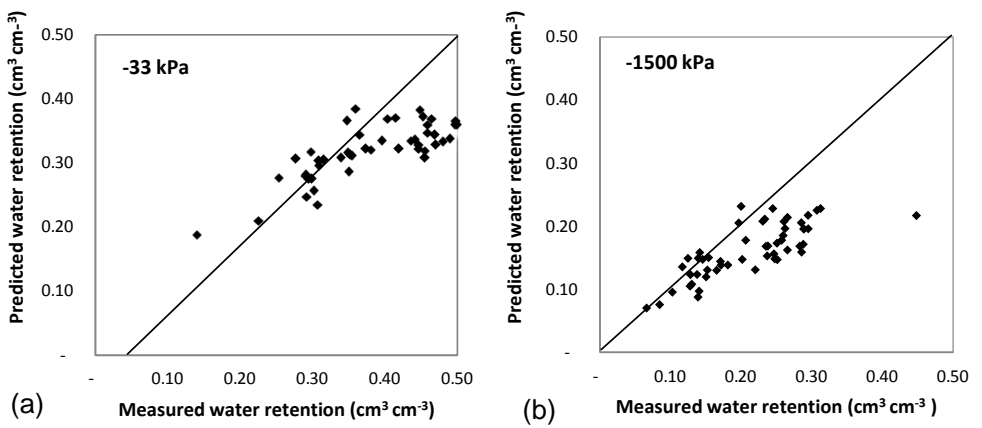

Figure 2. Scatter plots of measured versus predicted soil water retention by Rosetta $\mathrm{H} 2$.

$Y=f\left(X_{1}, X_{2}, X_{3}, \ldots, X_{p}\right)$,

where $Y$ is the model output (or objective function) and $X=\left(X_{1}, \ldots, X_{\mathrm{p}}\right)$ is the input variable set.

$V(Y)=V(E(Y \mid X))+E(\operatorname{Var}(Y \mid X))$

where $V(Y)$ is the total variance in the model, $V(E(Y \mid X))$ and $E(\operatorname{Var}(Y \mid X))$ signify variance in the conditional expected value and expected value of the conditional variance, respectively. When the input variables $X_{i}$ are independent, the variance decomposition of the model is

$V(Y)=\sum_{i=1}^{p} V_{i}+\sum_{i} \sum_{j} V_{i j}+\sum_{i} \sum_{j} \sum_{p} V_{i j p}+\ldots+V_{1,2,3, \ldots p}$

$V_{i}=V\left[E\left(Y \mid X_{i}\right)\right]$

$V_{i j}=V\left[E\left(Y \mid X_{i} X_{j}\right)\right]-V_{i}-V_{j}$

$V_{i j p}=V\left[E\left(Y \mid X_{i}, X_{j}, X_{p}\right)\right]-V_{i j}-V_{i p}-V_{j p}-V_{i}-V_{j}-V_{p}$,

where $V_{i}$ is the proportion of variance due to variable $X_{i}$. Dividing $V_{i}$ by $V(Y)$ produces the expression of the firstorder sensitivity index $\left(S_{i}\right)$, such that

$S_{i}=\frac{V_{i}}{V(Y)}=\frac{V\left[E\left(Y / X_{i}\right)\right]}{V(Y)}$.

The term $S_{i}$ is the measure that guarantees an informed choice in cases where the factors are correlated and interact (Saltelli and Tarantola, 2002). This index is always between 0 and 1, and represents a proper measurement of the sensitivity used to classify the input variables in order of importance (Saltelli and Tarantola, 2002).

In order to quantify variation in the sensitivity index $\left(V_{\mathrm{Si}}\right)$ of an input factor $X_{i}$, we fixed it at $X_{i}=X_{i}^{*}\left(X_{i}^{*}\right.$ : the average when the variable follows the normal distribution and the median when the variable follows the lognormal distribution). In order to calculate how much this assumption changed the variance of $Y$, we used the following formula:

$V_{\mathrm{Si}}=\left(\frac{V[E(Y / X)]}{V(Y)}-\frac{V\left[E\left(Y / X_{i}=X_{i}^{*}\right)\right]}{V(Y)}\right) \cdot 100$.
Table 3. Evaluation criteria of water retention pedotransfer functions (PTFs) at -33 and $-1500 \mathrm{kPa}$.

\begin{tabular}{lllrr}
\hline & & & $-33 \mathrm{kPa}$ & $-1500 \mathrm{kPa}$ \\
\hline \multirow{2}{*}{$\mathrm{ME}\left(\mathrm{cm}^{3} \mathrm{~cm}^{-3}\right)$} & Point PTF & MLR & 0.0188 & 0.0261 \\
& Parametric PTF & MNLR & -0.0016 & -0.0020 \\
& Rosetta & H1 & -0.0902 & -0.0458 \\
& & H2 & -0.0728 & -0.0436 \\
& & H3 & -0.0991 & -0.0552 \\
\hline RMSE $\left(\mathrm{cm}^{3} \mathrm{~m}^{-3}\right)$ & Point PTF & MLR & 0.0414 & 0.0444 \\
& Parametric PTF & MNLR & 0.0613 & 0.0605 \\
& Rosetta & H1 & 0.1170 & 0.0738 \\
& & H2 & 0.0970 & 0.0636 \\
& & H3 & 0.1280 & 0.0749 \\
\hline$d\left(\mathrm{~cm}^{3} \mathrm{~cm}^{-3}\right)$ & Point PTF & MLR & 0.9975 & 0.9911 \\
& Parametric PTF & MNLR & 0.9938 & 0.9775 \\
& Rosetta & H1 & 0.9623 & 0.9427 \\
& & H2 & 0.9775 & 0.9597 \\
& & H3 & 0.9519 & 0.9331 \\
\hline
\end{tabular}

In addition, combining the RMSE and $S_{i}$ enabled us to detect the contribution of each variable to improvement in the quality of prediction of the PTFs.

\section{Results and discussion}

In Table 3, most of the PTFs underestimated SWR except for the point PTF at the two pressure points $(-33$ and $-1500 \mathrm{kPa})$. The Rosetta $\mathrm{H} 2$ model, which considers only texture as an input, gave ME values closer to zero than the $\mathrm{H} 1$ and $\mathrm{H} 3$ models $\left(-0.0728\right.$ and $-0.0436 \mathrm{~cm}^{3} \mathrm{~cm}^{-3}$ at -33 and $-1500 \mathrm{kPa}$, respectively).

The poor ME values indicated better estimates of PTFs. They were produced after the application of point PTFs followed by parametric PTFs (Fig. 2).

Among the five tested models in the Lower Cheliff soils, the point PTFs (MLR) derived from a database taken from some Algerian soils had the lowest RMSE values ( 0.041 and $0.044 \mathrm{~cm}^{3} \mathrm{~cm}^{-3}$ at -33 and $-1500 \mathrm{kPa}$, respectively). Performances equivalent or superior to PTFs derived by multiple regression methods have been reported in some studies 

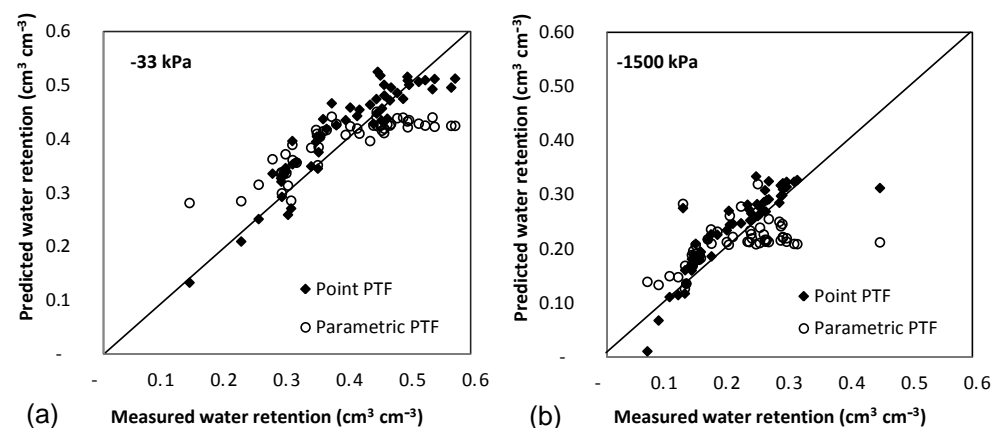

Figure 3. Scatter plots of measured soil water retention versus predicted soil water retention.
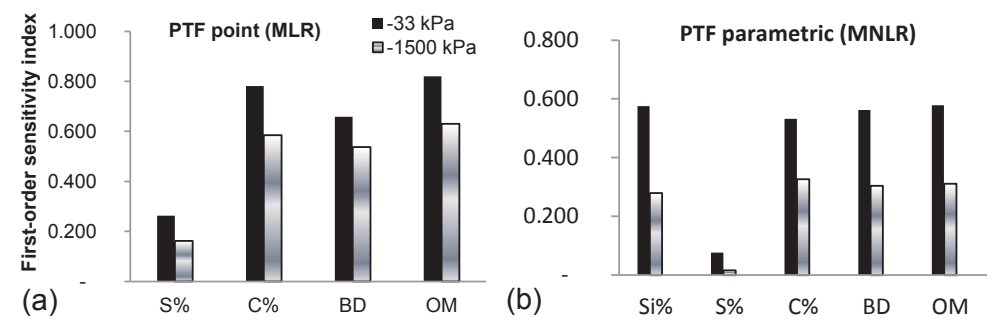

Figure 4. First-order sensitivity index.

(Minasny et al., 1999; Nemes et al., 2003). The nonlinear models (parametric PTFs), however, gave a better estimation than the Rosetta models based on ANN (RMSE: 0.0613 and $0.0605 \mathrm{~cm}^{3} \mathrm{~cm}^{-3}$ at -33 and $-1500 \mathrm{kPa}$, respectively). The RMSE and ME values of the three Rosetta models also showed that $\mathrm{H} 2$ was better than $\mathrm{H} 1$ or $\mathrm{H} 3$ (Table 3, Fig. 3).

The index of agreement results showed that point PTFs were more suitable for Lower Cheliff soils than parametric PTFs (Table 3) with values of 0.9975 and $0.9911 \mathrm{~cm}^{3} \mathrm{~cm}^{-3}$, respectively. Similar comparisons in different regions were undertaken by Minasny et al. (1999), Tomasella et al. (2003) and Ghorbani Dashtaki et al. (2010), who all reported similar differences between these two PTF approaches. As Table 3 shows, there was no significant difference in RMSE values between the parametric PTFs and Rosetta $\mathrm{H} 2$ at $-1500 \mathrm{kPa}$ (RMSE: $0.0605 \mathrm{~cm}^{3} \mathrm{~cm}^{-3}$ and $0.0636 \mathrm{~cm}^{3} \mathrm{~cm}^{-3}$, respectively).

\subsection{Sensitivity index before textural grouping}

In the development of PTFs, using PSD as an input is the usual approach (texture as an overall expression of PSD, clay, silt and sand content) and its contribution is fundamental to understanding the process of retaining water at different pressure points, although various physical and chemical characteristics are used to describe the SWR curve, such as BD and $\mathrm{OM}$.

The importance of each input variable was assessed by the first-order $S_{i}$. It was clear for the PTFs developed that OM \% and clay percentages $(\mathrm{C} \%)$ were the variables with the great- est impact (Fig. 4). For the point PTFs (MLR), the most sensitive estimations were at two pressure points $\left(S_{i}: 0.821\right.$ and 0.782 at $-33 \mathrm{kPa}$, and 0.630 and 0.585 at $-1500 \mathrm{kPa}$ for $\mathrm{OM} \%$ and $\mathrm{C} \%$, respectively. After OM, the percentage of silt $\left(S_{i} \%\right)$ was second in importance in parametric PTFs $(0.576$ at $-33 \mathrm{kPa})$ followed by BD and C (Fig. 2). The $S_{i}$ values placed sand content in third place in the MLR $(0.262 ; 0.162)$, indicating that its impact on the parametric model was almost insignificant, with very low values $\left(S_{i}: 0.077 ; 0.017\right)$ at -33 and $-1500 \mathrm{kPa}$, respectively).

The prediction quality of point PTFs (MLR) can be explained, first, by taking into account the basic characteristics of soil as an input from the textural and structural information given by the BD. Second, point PTFs (MLR) are based mainly on these input variables, unlike parameter PTFs (MNLR), which have inputs other than texture and $\mathrm{BD}$, as well as other parameters (VG parameters: $\theta_{\mathrm{r}}, \theta_{\mathrm{s}}, \alpha, n$ ).

\subsection{Sensitivity and uncertainty analysis after the textural grouping}

The sensitivity of the multiple regression methods (linear and nonlinear) used to develop PTFs from basic soil characteristics for estimating SWR for different textural classes was analysed. We grouped the samples into three classes of particles (Fig. 1b) in line with FAO (1990) guidelines: very fine (12 samples), fine (31 samples) and medium (10 samples).

The results showed that after the textural grouping, there was an improvement in the quality estimation of PTFs in only the medium class. A better prediction at $-1500 \mathrm{kPa}$ 
Table 4. Variation of first-order sensitivity index $\left(S_{i}\right)$ in the different textural (Tex.) classes.

\begin{tabular}{|c|c|c|c|c|c|c|c|c|c|c|c|c|}
\hline & & \multirow{2}{*}{$\begin{array}{l}\text { Tex. } \\
\text { class }\end{array}$} & \multicolumn{2}{|c|}{$\mathrm{Si}(\%)$} & \multicolumn{2}{|c|}{$\mathrm{S}(\%)$} & \multicolumn{2}{|c|}{$\mathrm{C}(\%)$} & \multicolumn{2}{|c|}{$\mathrm{BD}\left(\mathrm{g} \mathrm{cm}^{-3}\right)$} & \multicolumn{2}{|c|}{ OM (\%) } \\
\hline & & & $V_{\mathrm{Si}}$ & A.E. & $V_{\mathrm{Si}}$ & A.E. & $V_{\mathrm{Si}}$ & A.E. & $V_{\mathrm{Si}}$ & A.E. & $V_{\mathrm{Si}}$ & A.E. \\
\hline \multirow{6}{*}{ RML } & \multirow{3}{*}{ at $-33 \mathrm{kPa}$} & VF & \multicolumn{2}{|c|}{ Abs } & -1.2 & & \multicolumn{2}{|l|}{-0.4} & -50.5 & - & \multicolumn{2}{|l|}{4.6} \\
\hline & & $\mathrm{F}$ & \multicolumn{2}{|c|}{ Abs } & -43.2 & - & -10.7 & - & -39.9 & - & 0.2 & \\
\hline & & M & \multicolumn{2}{|c|}{ Abs } & -103.3 & - & -27.5 & + & -44.4 & + & -5.7 & \\
\hline & at $-1500 \mathrm{kPa}$ & VF & \multicolumn{2}{|c|}{ Abs } & -0.3 & & 0.9 & & -27.3 & - & 1.1 & \\
\hline & & $\mathrm{F}$ & \multicolumn{2}{|c|}{ Abs } & -46.2 & - & -20.7 & - & -41.6 & - & 0.1 & \\
\hline & & M & \multicolumn{2}{|c|}{ Abs } & -86.4 & - & -52.9 & - & -22.9 & - & -2.3 & \\
\hline \multirow[t]{6}{*}{ MNLR } & at $-33 \mathrm{kPa}$ & VF & \multicolumn{2}{|l|}{0.4} & -0.2 & & \multicolumn{2}{|l|}{0.1} & \multicolumn{2}{|l|}{-00.1} & \multicolumn{2}{|l|}{-0.05} \\
\hline & & $\mathrm{F}$ & \multicolumn{2}{|l|}{-1.6} & -40.9 & - & \multicolumn{2}{|l|}{-1.1} & -2.5 & & \multicolumn{2}{|l|}{-0.1} \\
\hline & & $\mathrm{M}$ & \multicolumn{2}{|l|}{15.0} & -5.2 & & 15.1 & + & 21.6 & + & 22.3 & + \\
\hline & at $-1500 \mathrm{kPa}$ & VF & \multicolumn{2}{|l|}{-4.6} & -0.3 & & \multicolumn{2}{|l|}{-1.8} & \multicolumn{2}{|l|}{-1.4} & \multicolumn{2}{|l|}{-0.5} \\
\hline & & $\mathrm{F}$ & 28.6 & + & 18.9 & - & \multicolumn{2}{|l|}{4.6} & \multicolumn{2}{|l|}{0.4} & \multicolumn{2}{|l|}{0.1} \\
\hline & & M & -36.7 & - & -16.7 & - & -22.6 & - & \multicolumn{2}{|l|}{8.9} & \multicolumn{2}{|l|}{-8.4} \\
\hline
\end{tabular}

Abs: absent in the model, $V_{\mathrm{Si}}$ : variation first sensitivity index, A.E.: improving estimation.
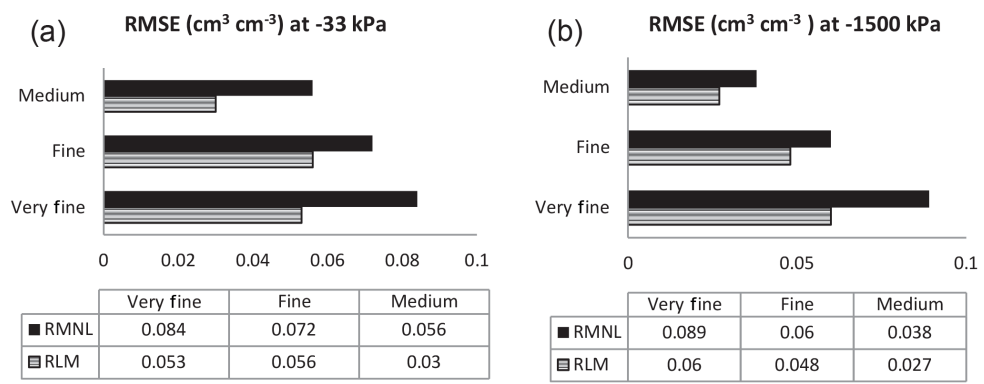

Figure 5. Root mean square error (RMSE) values calculated for the different textural classes.

was provided by point PTFs (RMSE $=0.027 \mathrm{~cm}^{3} \mathrm{~cm}^{-3}$ ) and parametric PTFs $\left(\mathrm{RMSE}=0.038 \mathrm{~cm}^{3} \mathrm{~cm}^{-3}\right)$ at $-1500 \mathrm{kPa}$ (Fig. 5).

\subsubsection{Texture}

After textural grouping, the MLR and MNLR PTFs developed were always sensitive, mainly to the sand fraction in the fine and medium classes (Table 4). The variation in the first $S_{i}$ in the point PTFs was significantly greater in the medium-texture class at the two pressure points $(-33$ and $-1500 \mathrm{kPa})$. In the MNLR, sand had the most influence, particularly with regard to the fine class $(-40.9,18.9 \%$ at -33 and $1500 \mathrm{kPa})$ and the medium class $(-16.7 \%$ at $-1500 \mathrm{kPa})$.

The $S_{i}$ of a variable quantifies the influence of its uncertainty on the output. This is the part of the variability output explained by the variability input. What was confirmed after calculating the variation in the first-order $S_{i}$ was that the PTFs developed were still more influenced by the variability in sand at $-33 \mathrm{kPa}$ than at $-1500 \mathrm{kPa}$. This impact could be explained by the irregularity of the dispersion of sand content in the validation database, with a coefficient of variation $(\mathrm{CV})$ of about $119 \%$ compared with the other input variables $(33,18,9$ and $57 \%$ for clay, silt, $\mathrm{BD}$ and $\mathrm{OM}$, respectively). This heterogeneity in the sand data series clearly influenced the uncertainty of the PTF response.

Looking at the matrix correlation (Table 5), the clay and silt fractions were significantly correlated with sand content. Saltelli and Tarantola (2002) observed that when $X_{1}$ and $X_{2}$ were correlated with a third factor, $X_{3}$, the $S_{i}$ calculated depended on the force of this correlation as well as the distribution of $X_{3}$. In this case, the index power could be influenced by this statistical association, as it explains the higher value difference of index variation in the sand percentage compared with the other variables.

We observed that point PTF (MLR) produced a lower error of estimation when the variation of the first-order $S_{i}$ for sand was the most important (MLR in the medium class: RMSE 0.030 and $0.027 \mathrm{~cm}^{3} \mathrm{~cm}^{-3}$ with $V_{\mathrm{Si}}-103$ and $86.4 \%$ at -33 and $-1500 \mathrm{kPa}$, respectively). A negative $S_{i}$ variation in sand content when the latter was fixed was apparent in all texture classes (Table 4). This could be explained by the proportional relationship between sand and clay content, particularly in the validation dataset with a dominant clay texture. Insignificant sensitivity of sand was recorded for the very fine 
Point PTFs

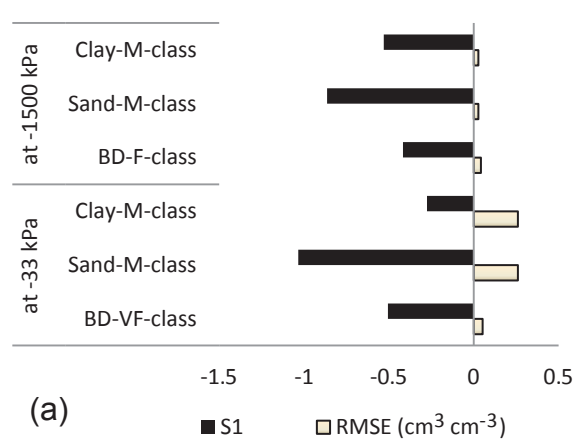

Parametric PTFs

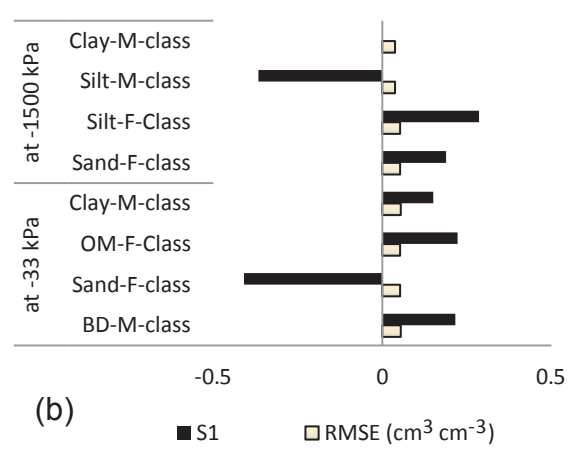

Figure 6. Variation in first sensitivity index with RMSE after textural grouping.

Table 5. Pearson correlation matrix between basic soil characteristics in the validation dataset of 53 soil samples.

\begin{tabular}{lrrrrr}
\hline Variables & $\begin{array}{r}S_{\mathrm{i}} \\
(\%)\end{array}$ & $\begin{array}{r}\mathrm{C} \\
(\%)\end{array}$ & $\begin{array}{r}\mathrm{S} \\
(\%)\end{array}$ & $\begin{array}{r}\mathrm{BD} \\
\left(\mathrm{g} \mathrm{cm}^{-3}\right)\end{array}$ & $\begin{array}{r}\mathrm{OM} \\
(\%)\end{array}$ \\
\hline Si \% & 1 & & & & \\
$\mathrm{~S} \%$ & -0.334 & 1 & & & \\
$\mathrm{C} \%$ & -0.159 & -0.878 & 1 & & \\
$\mathrm{BD}\left(\mathrm{g} \mathrm{cm}^{-3}\right)$ & 0.164 & -0.185 & 0.11 & 1 & \\
$\mathrm{OM}(\mathrm{g} / 100 \mathrm{~g})$ & -0.174 & -0.166 & 0.263 & -0.19 & 1 \\
\hline
\end{tabular}

The values in bold differ from 0 to a level of significance $\alpha=0.05$, Si: silt, S: sand, C: clay, BD: bulk density, OM: organic matter.

texture. Rawls et al. (2003) observed that $10 \%$ of sand provides an increase in SWR at low clay content and a decrease in SWR at high clay content of more than $50 \%$.

The relationship between the SWR curve parameters of VG (especially $n$ and $\alpha$ ) and PSD has been examined in many studies (e.g. Minasny and McBratney, 2007; Benson et al., 2014) in order to explain why the sand impact increases in the fine-texture class in parametric PTFs. It could be explained by the predominant presence of sand and clay content as inputs in parametric PTFs. For soils with clay content between 35 and $70 \%$, water content is greatly influenced by the percentage of sand in the soil (Loosvelt et al., 2013).

In addition, when the sand content of a sample increased to $60 \%$, the drying rate was faster and water absorbing ability was weaker than with the low sand content. When sand content falls to $20 \%$, the small pores occupy a large part of the pore structure, making the soil compact (Hao et al., 2015).

In the medium-texture class, there was increasing accuracy in PTFs at $-33 \mathrm{kPa}$ after fixing the clay content. This could be explained by the reduced clay percentage in the medium class (mean of clay $=23 \%$ ), which produced fewer errors at $-33 \mathrm{kPa}$.

The accuracy of the PTFs decreased when they were applied to some soil samples with a clay content $>60 \%$ (Fig. 5). In the very fine class, insignificant sensitivity was recorded at all pressures defined in this study. In this class, the variation in clay was much lower because it is only the dominant solid fraction, which could explain the smaller variation in $S_{i}$ after fixing the clay percentage. The greatest impact of clay (\%) was observed at $-1500 \mathrm{kPa}$ in the point and parametric PTFs in different textural classes (Fig. 6). The clay content of soils is a major predictor for modelling the permanent wilting point of soils (Minasny et al., 1999).

The silt percentage was introduced as an explanatory variable only in parametric PTFs (MNLR). This fraction is known for its ability to retain water at high and medium soil water potentials. The GSA showed that the silt percentage had a stronger impact on the estimation of parametric PTFs at $-1500 \mathrm{kPa}$ than at $-33 \mathrm{kPa}$ with the MNLR model. After textural grouping, an important variation in the first-order $S_{i}$ was observed in the medium class $(-36.7 \%$ to $-1500 \mathrm{kPa})$. The lowest values were recorded in the very fine class. It was clear that the silt percentage has an important role in estimating parameters of $\mathrm{VG}(\alpha, n)$, and that its use as an input influences the estimate in the medium and fine classes. There was an increasing accuracy, however, in the PTFs recorded in the fine class at $-1500 \mathrm{kPa}$. With silt and clay as inputs, there was a better estimation. Plant-available water content variation is more related to sand and silt than to clay content (Reichert et al., 2009).

\subsubsection{Bulk density}

This is the second most influential variable on the point PTF (MLR) response on all textural class. The important variation of sensitivity index is noted mainly in the very fine textural class at $-33 \mathrm{kPa}\left(V_{\mathrm{Si}}=-50,5 \%\right)$. In parametric PTFs, BD influenced the medium class at $-33 \mathrm{kPa}$. The accuracy of quality estimation at $-33 \mathrm{kPa}$ in the medium class when fixing the BD for the two PTF approaches (Table 4). The very-fine-textural class represented 16 surface samples $(0-30 \mathrm{~cm})$ with a dominance of clay texture. In a similar study on clay soils, volumetric water content (VWC) was highly related to the inverse of BD at field capacity (Bruand 
et al., 1996). The inclusion of BD as an input provides information on pore volume, which can influence the performance of PTFs when applied to soil with high clay content. In addition, the soil structural information characterised by BD measurements is an indirect measurement of pore space and is affected mainly by texture and structure. For structureless soils, primarily coarse- and medium-textured soils, the poresize distribution can be satisfactorily described by PSD. The medium texture is related in general to pore-size distribution, as large particles give rise to large pores between them, and therefore have a major influence on the SWR curve (Arya and Paris, 1981; Nimmo, 2004). With BD and texture as inputs in point PTF (MLR), predicted values very close to the experimental results are obtained.

\subsubsection{Organic matter content}

The less insignificant variation in the $S_{i}$ after textural grouping is related to OM content. This could be explained, first, by the poor OM content in the Algerian soil samples. Lal (1979) did not find any effect of OM content on SWR. Danalatos et al. (1994) attributed this to the generally low OM content in their samples. Second, homogeneity of the data for OM content in every textural class reduced the variation in PTF response. The increasing accuracy of parametric PTFs, however, was apparent for medium-textured soils at $-33 \mathrm{kPa}$, where $\mathrm{OM}$ was used as an input to predict $\theta_{\mathrm{s}}$. SWR at $-33 \mathrm{kPa}$ is affected more strongly by organic carbon than at $-1500 \mathrm{kPa}$ (Rawls et al., 2003). The sensitivity analysis conducted by Rawls et al. (2003) to study the role of OM content as a predictor showed that the SWR of coarse-textured soils is much more sensitive to changes in organic carbon than is the case with fine-textured soils. Bauer and Black (1981) found that the effect of organic carbon on SWR in disturbed samples was substantial in sandy soil and marginal in medium- and fine-textured soils.

\section{Conclusions}

The objective of this study was to analyse the sensitivity of estimating the SWR properties of Algerian soils using PTFs. We developed and validated point and parametric PTFs from basic soil properties using regression techniques and compared their predictive capabilities with the Rosetta models (H1, H2 and H3). The reliability tests showed that point PTFs produce more accurate estimations than parametric PTFs. The derived parametric PTFs, however, provided better estimates than the Rosetta models originally developed from a large intercontinental database.

The GSA showed that the mathematical formalism of the PTF models and their input variables reacted differently in terms of point pressure and textural class as follows:

- After textural grouping, the two PTF approaches developed (MLR and MNLR) were always sensitive primar- ily to the sand fraction in the fine and medium classes at $-33 \mathrm{kPa}$, rather than at $-1500 \mathrm{kPa}$.

- The results illustrated the accuracy of estimation at $-33 \mathrm{kPa}$ in the medium class for the two PTF approaches when fixing the clay percentage $(\mathrm{C} \%)$ and BD.

- The accuracy of PTFs decreased when they were applied to soil samples with a clay content $>60 \%$.

- The most insignificant variation in the $S_{\mathrm{i}}$ after textural grouping was related to the OM content in Algerian soils.

\section{Data availability}

The data are available via the following database: http://hdl. handle.net/2268/204146. Otherwise, interested parties may email the corresponding author for datasets.

Acknowledgements. The authors want to gratefully acknowledge the topical editor and reviewers.

Edited by: D. Dunkerley

Reviewed by: S. Barontini and one anonymous referee

\section{References}

Arya, L. M. and Paris, J. F.: A physic empirical model to predict the soil moisture characteristic from particle-size distribution and bulk density data, Soil Sci. Soc. Am. J., 45, 1023-1030, 1981.

Bauer, A. and Black, A. L.: Soil carbon, nitrogen, and bulk density comparisons in two cropland tillage systems after 25 years and in virgin grassland, Soil Sci. Soc, Am. J., 45, 1166-1170, 1981.

Benson, C., Chiang, I., Chalermyanont, T., and Sawangsuriya, A.: Estimating van Genuchten parameters $\alpha$ and $n$ for clean sands from particle size distribution data, Soil Behavior Fundamentals to Innovations in Geotechnical Engineering, GeoCongress 2014, ASCE, Reston, VA, 410-427, 2014.

Botula, Y. D., Van Ranst, E., and Cornelis, W. M.: Pedotransfer functions to predict water retention of soils from the humid tropics: a review, Revista Brasileira de Ciencia do Solo, 38, 679-698, 2014.

Bruand, A., Duval, O., Gaillard, H., Darthout, R., and Jamagne, M.: Variabilité des propriétés de rétention en eau des sols: importance de la densité apparente, Etude et Gestion des Sols, 3, 27-40, 1996.

Bruand, A., Perez-Fernandez, P., Duval, O., Quetin, P., Nicoullaud, B., Gaillard, H., Raison, L., Pessaud, J. F., and Prud'homme, L.: Estimation des propriétés de rétention en eau des sols: utilisation de classe de pédotransfert après stratifications texturale et texturo-structurale, Etud. Gest. Sols, 9, 105-125, 2002.

Danalatos, N. G., Kosmas, C. S., Driessen, P. M., and Yassoglou, N.: Estimation of the draining soil moisture characteristics from standard data as recorded in soil surveys, Geoderma, 64, 155165, 1994. 
Deng, H. L., Ye, M., Schaap, M. G., and Khaleel, R.: Quantification of uncertainty in pedotransfer function-based parameter estimation for unsaturated flow modeling, Water Resour. Res., 45, W04409, doi:10.1029/2008WR007477, 2009.

FAO - Food and Agriculture Organisation: Guidelines for soil description, 3rd Edn., FAO/ISRIC, Rome, 1990.

Ghanbarian-Alavijeh, B. and Liaghat, A. M.: Evaluation of soil texture data for estimating soil water retention curve, Can. J. Soil Sci., 89, 461-471, 2009.

Ghorbani Dashtaki, S., Homaee, M., and Khodaverdiloo, H.: Derivation and validation of pedotransfer functions for estimating soil water retention curve using a variety of soil data, Soil Use Manage, 26, 68-74, 2010.

Grunwald, S., McSweeney, K., Rooney, D. J., and Lowery, B.: Soil layer models created with profile cone penetrometer data, Geoderma, 103, 181-201, 2001.

Hao, D. R., Liao, H. J., Ning, C. M., and Shan, X. P.: The microstructure and soil water characteristic of unsaturated loess. Unsaturated Soil Mechanics - from Theory to Practice, Proceedings of the 6th Asia Pacific Conference on Unsaturated Soils, 2326 October 2015, Guilin, China, 163-167, doi:10.1201/b1924822, 2015.

Jacques, J., Lavergne, C., and Devictor, N.: Sensitivity analysis in presence of model uncertainty and correlated inputs, Reliabil. Eng. Syst. Safe., 91, 1126-1134, 2006.

Jonasson, S. A.: Estimation of the Van Genuchten parameters from grain-size distribution, Proc. of the Int. Workshop Indirect Methods for Estimating the Hydraulic Properties of Unsaturated Soils, 11-13 October 1989, Riverside, CA, Univ. of California, Riverside, 443-451, 1992.

Kay, B. D., da Silva, A. P., and Baldock, J. A.: Sensitivity of soil structure to changes in organic carbon content: predictions using pedotransfer functions, Can. J. Soil Sci., 77, 655-667, 1997.

Lal, R.: Physical properties and moisture retention characteristics of some Nigerian soils, Geoderma 21, 209-223, 1979.

Lee, T.-K. and Ro, H.-M.: Estimating soil water retention function from its particle-size distribution, Geosciences J., 18, 219-230, 2014.

Lin, H. S., McInnes, K. J., Wilding, L. P., and Hallmark, C. T.: Effects of soil morphology on hydraulic properties: II. Hydraulic pedotransfer functions, Soil Sci. Soc. Am. J., 63, 955-961, 1999.

Loosvelt, L., Vernieuwe, H., Pauwels, V. R. N., De Baets, B., and Verhoest, N. E. C.: Local sensitivity analysis for compositional data with application to soil texture in hydrologic modelling, Hydrol. Earth Syst. Sci., 17, 461-478, doi:10.5194/hess-17-4612013, 2013.

Mayr, T. and Jarvis, N. J.: Pedotransfer functions to estimate soil water retention parameters for a modified Brooks-Corey type model, Geoderma, 91, 1-9, 1999.

Minasny, B. and McBratney, A. B.: Uncertainty analysis for pedotransfer functions, Eur. J. Soil Sci., 53, 417-429, 2002.

Minasny, B. and McBratney, A. B.: Estimating the water retention shape parameter from sand and clay content, Soil Sci. Soc. Am. J., 71, 1105-1110, 2007.

Minasny, B., McBratney, A. B., and Bristow, K.: Comparison of different approaches to the development of pedotransfer function for water-retention curves, Geoderma, 93, 225-253, 1999.
Mirus, B. B.: Evaluating the importance of characterizing soil structure and horizons in parameterizing a hydrologic process model, Hydrol. Process., 29, 4611-4623, 2015.

Moeys, J., Larsbo, M., Bergström, L., Brown, C. D., Coquet, Y., and Jarvis, N. J.: Functional test of pedotransfer functions to predict water flow and solute transport with the dualpermeability model MACRO, Hydrol. Earth Syst. Sci., 16, 20692083, doi:10.5194/hess-16-2069-2012, 2012.

Nemes, A., Schaap, M. G., and Wösten, J. H. M.: Functional evaluation of pedotransfer functions derived from different scales of data collection, Soil Sci. Soc. Am. J., 67, 1093-1102, 2003.

Nemes, A., Rawls, W. J., Pachepsky, Y. A., and van Genuchten, M. T.: Sensitivity analysis of the nonparametric nearest neighbor technique to estimate soil water retention, Vadose Zone J., 5, 1222-1235, 2006.

Nimmo, J. R.: Porosity and Pore Size Distribution, in: Encyclopedia of Soils in the Environment, edited by: Hillel, D., Elsevier, London, 295-303, 2004.

Pachepsky, Y. A. and Rawls, W. J.: Soil structure and pedotransfer function, Eur. J. Soil Sci., 54, 443-452, 2003.

Pachepsky, Y. A., Timlin, D., and Varallyay, G.: 1996, Artificial neural networks to estimate soil water retention from easily measurable data, Soil Sci. Soc. Am. J., 60, 727-733, 1996.

Pachepsky, Y. A., Rawls, W. J., and Timlin, D. J.: The current status of pedotransfer functions: Their accuracy, reliability, and utility in field and regional-scale modeling, in: Assessment of Non-point Source Pollution in the Vadose Zone, Geophys. Monogr. Ser., vol. 108, edited by: Corwin, D. L., Loague, K., and Ellsworth, T. R., AGU, Washington, D.C. 223-234, 1999.

Rawls, W. J. and Brakensiek, D. L.: Prediction of soil water properties for hydrologic modeling, Proc. Symp. Water shed Management in the Eighties, 30 April-1 May 1985, Denver, CO, Am. Soc. Civil Eng., New York, 293-299, 1985.

Rawls, W. J., Gish, T. J., and Brakensiek, D. L.: Estimating soil water retention from soil physical properties and characteristics, Adv. Soil Sci., 16, 213-234, 1991.

Rawls, W. J., Pachepsky, Y., and Ritchie, J.: Effect of soil organic carbon on soil water retention, Geoderma, 116, 61-76, 2003.

Reichert, J. M., Suzuki, L. E. A. S., Reinert, D. J., Horn, R., and Håkansson, I.: Reference bulk density and critical degree-ofcompactness for no-till crop production in subtropical highly weathered soils, Soil Till. Res., 102, 242-254, 2009.

Richards, L. A. and Fireman, M.: Pressure-plate apparatus for measuring moisture sorption and transmission by soils, Soil Sci., 56, 395-404, 1943.

Robinson, G. W.: A new method for the mechanical analysis of soils and other dispersions, J. Agric. Sci., 12, 306-321, doi:10.1017/S0021859600005360, 1922.

Saltelli, A. and Tarantola, S.: On the relative importance of input factors in mathematical models, J. Am. Stat. Assoc., 97, 702709, 2002.

Saltelli, A., Chan, K., and Scott, M. (Eds.): Sensitivity Analysis, in: Probability and Statistics Series, John Wiley and Sons, Ltd, Now York, 2000.

Saxton, K. E., Rawls, W. L., Rosenberger, J. S., and Papendick, R. I.: Estimating generalized soil-water characteristics from texture, Soil Sci. Soc. Am. J., 50, 1031-1036, 1986. 
Schaap, M. G. and Leij, F. J.: Using neural networks to predict soil water retention and soil hydraulic conductivity, Soil Till. Res., 47, 37-42, 1998.

Schaap, M. G., Leij, F. J., and van Genuchten, M. T.: Rosetta: A computer program for estimating soil hydraulic parameters with hierarchical pedotransfer functions, J. Hydrol., 251, 163-176, 2001.

Sobol, I. M.: On sensitivity estimation for nonlinear mathematical models, Matematicheskoe Modelirovanie (in Russian), translated in: Math. Model. Comput. Exp., 2, 112-118, 1990.

Stumpp, C., Engelhardt, S., Hofmann, M., and Huwe, B.: Evaluation of Pedotransfer Functions for Estimating Soil Hydraulic Properties of Prevalent Soils in a Catchment of the Bavarian Alps, Eur. J. Forest Res., 128, 609-620, 2009.

Tomasella, J., Hodnett, M. G., and Rossato, L.: Pedotransfer functions for the estimation of soil water retention in Brazilian soils, Soil Sci. Soc. Am. J., 64, 327-338, 2000.

Tomasella, J., Pachepsky, Y. A., Crestana, S., and Rawls, W. J.: Comparison of two techniques to develop pedotransfer functions for water retention, Soil Sci. Soc. Am. J., 67, 1085-1092, 2003.

Touil, S., Degré, A., and Chabaca, M. N.: Transposability of pedotransfer functions for estimating water retention of Algerian soils, Desalin. Water Treat., 57, 5232-5240, 2016.

Van Genuchten, M. T.: A closed-form equation for predicting the hydraulic conductivity of unsaturated soils, Soil Sci. Soc. Am. J., 44, 892-898, 1980.

Van Genuchten, M. T., Leij, F. J., and Lund, L. J.: Indirect methods for estimating the hydraulic proprieties of unsaturated soils, US Salinity Lab., Riverside, CA, 1992.

Vereecken, H., Feyen, J., Maes, J., and Darius, P.: Estimating the soil moisture retention characteristic from texture, bulk density, and carbon content, Soil Sci., 148, 389-403, 1989.

Vereecken, H., Diels, J., Vanorshoven, J., Feyen, J., and Bouma, J.: Functional evaluation of pedotransfer functions for the estimation on of soil hydraulic properties, Soil Sci. Soc. Am. J., 56, 1371-1378, 1992.
Vereecken, H., Weynants, M., Javaux, M., Pachepsky, Y., Schaap, M. G., and van Genuchten, M. T.: Using pedotransfer functions to estimate the van Genuchten-Mualem soil hydraulic properties: A review, Vadose Zone J., 9, 795-820, 2010.

Walkley, A. and Black, I. A.: An examination of the Degtjareff method for determining organic carbon in soils: Effect of variations in digestion conditions and of inorganic soil constituent, Soil Sci., 63, 251-263, 1934.

Williams, J., Prebble, R. E., Williams, W. T., and Hignett, C. T.: The influence of texture, structure and clay mineralogy on the soil moisture characteristic, Aust. J. Soil Res., 21, 15-32, 1983.

Willmott, C. J.: On the validation of models, Phys. Geogr., 2, 184194, 1981.

Willmott, C. J. and Wicks, D. E.: An empirical method for the spatial interpolation of monthly precipitation within California, Phys. Geogr., 1, 59-73, 1980.

Winfield, K. A., Nimmo, J. R., Izbicki, J. A., and MartinResolving, P. M.: Structural Influences on Water-Retention Properties of Alluvial Deposits, Vadose Zone J., 5, 706-719, 2006.

Wösten, J. H. M., Finke, P. A., and Jansen, M. J. W.: Comparison of class and continuous pedotransfer functions to generate soil hydraulic characteristics, Geoderma, 66, 227-237, 1995.

Wösten, J. H. M., Pachepsky, Y. A., and Rawls, W. J.: Pedotransfer functions: Bridging the gap between available basic soil data and missing soil hydraulic characteristics, J. Hydrol., 251, 123-150, 2001.

Yang, X. and You, X.: Estimating Parameters of Van Genuchten Model for Soil Water Retention Curve by Intelligent Algorithms, Appl. Math. Inf. Sci., 7, 1977-1983, 2013. 